\title{
Gastric cancer vaccines synthesized using a TLR7 agonist and their synergistic antitumor effects with 5 -fluorouracil
}

\author{
Xiaodong Wang ${ }^{1}{ }^{1}$, Yu Liư ${ }^{3}$, Yuwen Diao ${ }^{4}$, Ningning Gao ${ }^{1}$, Yanyan Wan ${ }^{3}$, Jingjing Zhong ${ }^{1}$, Huali Zheng ${ }^{1}$,
} Zhulin Wang ${ }^{1}$ and Guangyi Jin ${ }^{1,2^{*}}$

\begin{abstract}
Background: Vaccines play increasingly important roles in cancer treatment due to their advantages of effective targeting and few side effects. Our laboratory has attempted to construct vaccines by conjugating TLR7 agonists with tumor-associated antigens. Furthermore, immunochemotherapy has recently become an appealing approach to cancer therapy. 5-fluorouracil (5-FU), a commonly used chemotherapeutic agent, can reportedly potently and selectively kill tumor-associated MDSCs in vivo.
\end{abstract}

Methods: Gastric cancer vaccines were synthesized by the covalent attachment of our TLR7 agonist with the gastric cancer antigen MG7-Ag tetra-epitope, leading to T7 - ML (linear tetra-epitope) and T7 - MB (branched tetraepitope). Cytokines induced by the vaccines in vitro were assessed by ELISA. A tumor challenge model was created by treating BALB/C mice on either a prophylactic or therapeutic vaccination schedule. 5-FU was simultaneously applied to mice in the combination treatment group. CTL and ADCC activities were determined by the LDH method, while $\mathrm{CD}^{+} / \mathrm{CD}^{+}, \mathrm{CD}^{+} / \mathrm{CD}^{+}+$cells and MDSC $s$ were evaluated by flow cytometry.

Results: In vitro, rapid TNF-a and IL-12 inductions occurred in BMDCs treated with the vaccines. In vivo, among all the vaccines tested, T7 - MB most effectively reduced EAC tumor burdens and induced CTLs, antibodies and ADCC activity in BALB/C mice. Immunization with T7 - MB in combination with 5-FU chemotherapy reduced tumor sizes and extended long-term survival rates, mainly by improving $T$ cell responses, including $\mathrm{CTLS}, \mathrm{CD}^{+} / \mathrm{CD}^{+}$and $^{\mathrm{CD}} 3^{+} / \mathrm{CD}^{+}$ T cells. 5-FU also enhanced the T7 - MB efficiency by reversing immunosuppressive factors, i.e., MDSCs, which could not be validly inhibited by the vaccines alone. In addition, T7 - MB repressed tumor growth and immune tolerance when the therapeutic schedule was used, although the effects were weaker than those achieved with either T7 - MB alone or in combination with 5-FU on the prophylactic schedule.

Conclusions: A novel effective gastric cancer vaccine was constructed, and the importance of branched multiple antigen peptides and chemical conjugation to vaccine design were confirmed. The synergistic effects and mechanisms of T7 - MB and 5-FU were also established, observing mainly T cell activation and MDSC inhibition.

Keywords: Gastric cancer, Vaccine, TLR7, MG7-Ag, 5-Fluorouracil

\footnotetext{
*Correspondence: gyjin@szu.edu.cn

${ }^{1}$ School of Pharmaceutical Sciences, Shenzhen University Health Science

Center, Shenzhen 518060, Guangdong, China

Full list of author information is available at the end of the article
} 


\section{Background}

Toll-like receptors (TLRs), expressed in a variety of immune cells, are recognized for their ability to initiate immune responses upon exposure to specific pathogenassociated molecular patterns (PAMPs), including bacterial lipopolysaccharide (LPS) and flagellin [1]. Recently, TLRs have also been closely related to immune activation against diverse cancers, as at least three types of TLR agonists have been approved by the FDA for use in cancer treatment: bacillus Calmette-Guérin, monophosphoryl lipid A (MPL) and imiquimod [2]. Imiquimod, a typical small-molecule TLR7 agonist with a non-nucleoside imidazoquinoline structure, was approved for the treatment of patients with superficial basal cell carcinoma in 2004 [3] and has also been applied as an adjuvant in investigations on antitumor vaccines. A phase II trial demonstrated that imiquimod/TA-CIN (a recombinant HPV fusion protein vaccine) engendered $\mathrm{T}$ cell infiltration and lesion regression [4]. Imiquimod also exerts therapeutic effects on chronic myeloid leukemia (CML) patients when administered together with a granulocyte macrophage-colony stimulating factor (GM-CSF) producingvaccine derived from a CML cell line [5]. Activation of TLR7 signaling in immune cells depends mostly on myeloid differentiation factor 88 (MyD88) and downstream transcription factors, such as members of the interferon (IFN)-regulatory factor (IRF) family and nuclear factor- $\mathrm{kB}(\mathrm{NF}-\mathrm{kB})$, resulting in the release of stimulatory molecules and immune system stimulation [6]. In addition to imiquimod, UC-1V150 is another well-studied TLR7 agonist that increases the levels of proinflammatory cytokines by conjugation to phospholipids [7]. We have constructed a series of vaccines by covalently attaching a small-molecule TLR7 agonist to a gastric cancer antigen, leading to immunogenicity stimulation and tumor inhibition when introduced to animal models [8]. Our laboratory recently synthesized a novel TLR7 agonist (T7) that enhanced the effectiveness of chemotherapeutic agents in a murine model of $\mathrm{T}$ cell lymphoma [9].

Tumor-associated antigens (TAAs) are specifically expressed in tumor cells and can be recognized by the immune system and applied as immunotherapy targets against cancer [10]. Some important tumor antigens have been detected to evaluate the diagnosis and prognosis of gastric cancer for decades, such as CEA (carcinoembryonic antigen), CA19-9 (carbohydrate antigen 19-9) and CA125 (carbohydrate antigen 125) [11]. Monoclonal gastric cancer 7 antigen (MG7-Ag) is a TAA in gastric cancer with a much higher specificity and selectivity than those of previously discovered antigens. MG7-Ag is substantially important in the progression of a tumor, whose expression in gastric mucosa is highly likely to be linked with atypical hyperplasia and malignant changes $[12,13]$.
In this study, we constructed novel gastric cancer vaccines using collaborative applications of our TLR7 agonist (T7) and the MG7-Ag tetra-epitope. Herein, using multiple antigen peptides (MAPs) of the MG7-Ag epitope, with an especially branched architecture, substantially improved our previous vaccine designs. The efficiencies of vaccines on eliciting humoral and cellular immune responses were demonstrated by cytokine detection, antibody titer determination, antibodydependent cell-mediated cytotoxicity (ADCC) and cytotoxic $\mathrm{T}$ lymphocyte (CTL) activity and flow cytometry. A tumor challenge assay was also carried out to confirm that T7 - MB (conjugation of T7 and the MG7-Ag branched tetra-epitope) was the most potent agent in reversing tumor tolerance. Next, the synergistic effects of T7 - MB and 5-fluorouracil (5-FU, a commonly used chemotherapeutic agent), administered on both prophylactic and therapeutic vaccination schedules, on tumor inhibition were displayed by variations in tumor volumes, tumor weights and long-term survivals.

\section{Methods \\ Chemical synthesis}

T7 was synthesized as described before [9]. For the syntheses of peptides, $1.0 \mathrm{mmol} / \mathrm{g}$ 2-chlorotrityl chloride resin (GL BIO Company, Shanghai, China) was loaded as the solid support, and the following N-protected Fmoc amino acids were used as the functionalized amino acids: Fmoc-Lys(Boc)-OH, Fmoc-Thr(tBu)-OH, Fmoc-His(Trt)$\mathrm{OH}$, Fmoc-Val-OH, Fmoc-Pro-OH (GL BIO Company) and T7. The coupling reagent was 2-(1,H-benzotriazol1-yl)-1,1,3,3-tetramethyluronium hexafluorophosphate. Fmoc-Lys(Boc)-OH was first coupled to the resin, while successive amino acids were applied at 1 or 4 equal molar quantities for synthesis of the MG7-Ag linear tetraepitope (ML) or the MG7-Ag branched tetra-epitope (MB). Fmoc deprotection was performed in a solution containing piperidine and dimethylformamide in a ratio of $2 / 8(\mathrm{v} / \mathrm{v})$. Disaggregation of the peptides from the resin was implemented in a mixture of trifluoroacetic acid, phenol, water and triisopropylsilane in a ratio of $88 / 5 / 5 / 2$ (v/v) for $3.5 \mathrm{~h}$. The harvested peptides were precipitated by cold diethyl ether, dissolved by $0.1 \%$ trifluoroacetic acid in water/acetonitrile and lyophilized. Finally, electrospray mass spectrometry was completed to identify the structures of the peptides, and analytical high-performance liquid chromatography (C18 column, $5 \mu \mathrm{m}, 300 \AA$, $10.0 \times 200 \mathrm{~mm}$ ) was used to further confirm a purity of at least $95 \%$ (UV detection at 214 and $254 \mathrm{~nm}$ ).

\section{Cytokine assays}

Mouse bone marrow dendritic cells (BMDCs) were generated from the femurs and tibias of BALB/c mice as 
described previously [8]. BMDCs were cultured in X-vivo 15 medium (Lonza, Walkersville, WV, USA) containing $10 \mathrm{ng} / \mathrm{mL}$ GM-CSF and $10 \mathrm{ng} / \mathrm{mL}$ IL- 4 at $37^{\circ} \mathrm{C}$ for 6 days and then seeded in 96-well plates at a density of $5 \times 10^{4}$ cells per well. Vaccines were added at a final concentration of $5 \mu \mathrm{M}$ or $10 \mu \mathrm{M}$ and incubated for $24 \mathrm{~h}$. The cytokines TNF- $\alpha$ and IL-12 in the culture supernatants were quantified using Mouse TNF- $\alpha$ and IL-12 p70 ELISA Ready-SET-Go reagent sets (eBioscience, San Diego, CA, USA) according to the manufacturer's specifications. Briefly, an ELISA plate was first coated at $4{ }^{\circ} \mathrm{C}$ overnight with a capture antibody and then successively loaded with a blocking solution, the culture supernatant and a detection antibody for $1 \mathrm{~h}$ at room temperature. Finally, the substrate and stop solution were filled to obtain the optical density, which was recorded with a spectrophotometer (BioTek, Winooski, VT, USA) at $450 \mathrm{~nm}$.

\section{Tumor challenge model}

The animal protocol, approved by the Laboratory Animal Ethics Committee of Shenzhen University, was proposed to attenuate animal discomfort. Female 4-week-old (for prophylactic vaccination) and 6-week-old BALB/c (for therapeutic vaccination) mice were purchased from the Medical Laboratory Animal Center (Guangzhou, Guangdong, China). All mice were housed in specific pathogen-free conditions on a $12 \mathrm{~h}$ light/dark cycle, provided water and food ad libitum, and acclimated for 1 week before the formal experiments. Each BALB/c mouse was subcutaneously challenged on the right-hand side of its back with $1 \times 10^{7}$ ehrlich ascites carcinoma (EAC) cells, in which MG7-Ag expression was validated by western blot using an MG7-Ag antibody (a gift from Dr. Fan Daiming and Dr. Nie Yongzhan).

\section{Prophylactic vaccination schedule}

BALB/c mice were immunized with the vaccines, and PBS served as the control. Each mouse was subcutaneously administered $100 \mu \mathrm{g}$ of T7 - MB or equal molar quantities of the other vaccines every 2 weeks three times and challenged with EAC cells on day 0. Furthermore, $30 \mathrm{mg} / \mathrm{kg} 5$-FU was applied intraperitoneally every 3 days after the tumor challenge until day 21 (Fig. 1a). Tumor dimensions were measured with Vernier calipers every 3 days, and tumor volumes were calculated with the formula $\left(\mathrm{A} \times \mathrm{B}^{2}\right) / 2$, where $\mathrm{A}$ and $\mathrm{B}$ represented the larger and smaller dimensions of the tumor, respectively. All mice were sacrificed on day 21, and the tumors were removed and weighed. The tumor weights in each group were expressed as the percentages relative to the PBS control. Long-term survival was also evaluated until the mice died naturally.

\section{Therapeutic vaccination schedule}

$\mathrm{BALB} / \mathrm{c}$ mice were first subcutaneously challenged with EAC cells on day 0 . Next, $100 \mu$ g of T7 - MB or equal molar quantities of the other vaccines were administered on days 7 and 14, while $30 \mathrm{mg} / \mathrm{kg} \mathrm{5-FU} \mathrm{was} \mathrm{administered}$ every 3 days until day 21 (Fig. 1b). Tumor dimensions,

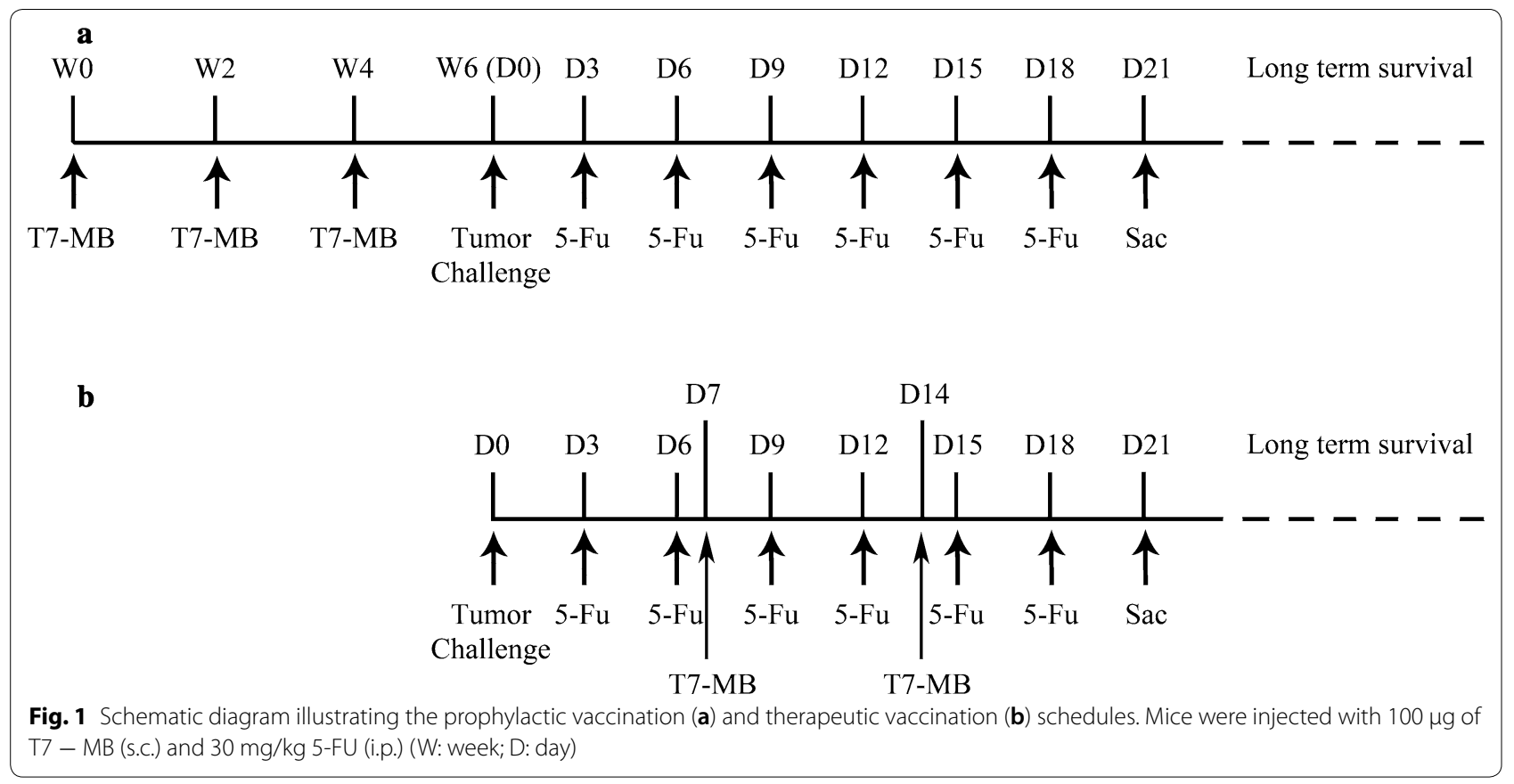


tumor weights and long-term survival rates were determined as described above.

\section{Determinations of CTLs}

Lymphocytes (effectors) were derived from the spleens of mice using Mouse Lymphocyte Separation Medium (Dakewe, Beijing, China) at the time of sacrifice. EAC tumor cells (targets) were co-cultured with lymphocytes at an effector-to-target cell ratio of 50:1 for $4 \mathrm{~h}$. Cytotoxicity was determined by the lactate dehydrogenase (LDH) method using the non-radioactive cytotoxicity assay (Promega, Madison, WI, USA) according to the manufacturer's specifications. Shortly thereafter, an ELISA plate was loaded with the culture supernatant, and substrate solution was added at room temperature for $30 \mathrm{~min}$. Finally, a stop solution was filled to obtain the optical density, which was recorded with a spectrophotometer (BioTek) at $490 \mathrm{~nm}$.

\section{Determinations of antibody titers}

Blood samples were collected from the mice after each immunization on the prophylactic vaccination schedule to obtain serum samples by centrifugation at $3000 \mathrm{~g}$ for $15 \mathrm{~min}$. Antibody titers were quantified by the ELISA method using an alkaline phosphate-conjugated detection antibody for total IgG (Millipore, Billerica, MA, USA). Briefly, an ELISA plate was first coated at $4{ }^{\circ} \mathrm{C}$ overnight with BSA-MG1 (sequence is BSA-KPHVHTK) and later successively loaded with a blocking solution for $2 \mathrm{~h}$ at room temperature, the serum samples (1:50 diluted) and a detection antibody for $1 \mathrm{~h}$. Finally, the p-NPP substrate (Millipore) and stop solution were filled to obtain the optical density, which was recorded with a spectrophotometer (BioTek) at $405 \mathrm{~nm}$.

\section{Determinations of ADCC activity}

Serum samples (1:25 diluted) were isolated from the mice at the time of sacrifice and then incubated with EAC tumor cells (targets) for $30 \mathrm{~min}$ at $37{ }^{\circ} \mathrm{C}$. Natural killer (NK) cells (effectors), separated from a normal BALB/c mouse using a Mouse NK Cell Separation Kit (Hao Yang, Tianjin, China), were co-cultured with antibody-labeled EAC cells at an effector-to-target cell ratio of 50:1 for $4 \mathrm{~h}$. Cytotoxicity was determined by the LDH method using the non-radioactive cytotoxicity assay (Promega) according to the specifications described above.

\section{Flow cytometry}

At the time of sacrifice, the mouse spleens were homogenized by repeated pipetting and filtered through a 70- $\mu \mathrm{m}$ nylon filter. Single-cell splenocyte suspensions were washed three times with FACS, stained with the appropriate antibodies at a final concentration of $1 \mu \mathrm{g} /$ $\mathrm{ml}$ at $4{ }^{\circ} \mathrm{C}$ overnight, and analyzed by FACSCalibur flow cytometry (BD Biosciences, San Jose, CA, USA). The following antibodies, purchased from eBioscience, were used for flow cytometry: CD3-Alexa Fluor 488, CD4PerCP Cy5.5, CD8a-PE, CD11b-Alexa Fluor 647 and Gr1-PerCP Cy5.5.

\section{Statistical analysis}

Data are expressed as the means \pm SEs for the indicated numbers of independently performed experiments. Oneway ANOVA was used for the determination of statistical significance, and differences were considered statistically significant at $P<0.05$.

\section{Results}

\section{Chemical synthesis and in vitro cytokine release} of vaccines

A novel TLR7 agonist (T7) (molecular weight: 444) was synthesized by our group as previously described [9] and used in the preparation of the other vaccines in this study (Fig. 2). Four peptides were obtained by the solid phase method using an Fmoc strategy: ML (molecular weight: 2945), MB (molecular weight: 3714), conjugation of T7 and ML (T7 - ML) (molecular weight: 3372), and conjugation of T7 and MB (T7 - MB) (molecular weight: 5420). The conjugations were constructed by covalent attachment of the carboxyl group in T7 and the amino group in the nitrogen terminus of peptides. Mass spectrometry and high-performance liquid chromatography were applied to confirm the structures and purities of the above compounds (Additional files 1, 2, 3, 4). Moreover, T7 and the MG7-Ag epitope were also assembled by commixing $\mathrm{T} 7$ and $\mathrm{ML}$ at a 1:1 ratio $(\mathrm{T} 7+\mathrm{ML})$ and $\mathrm{T} 7$ and $\mathrm{MB}$ at a $4: 1$ ratio $(\mathrm{T} 7+\mathrm{MB})$. Indicated concentrations of the vaccines were incubated with mouse BMDCs to determine their cytokine production abilities (Fig. 3). When BMDCs were exposed to ML or MB alone, no initiation of two cytokines (TNF- $\alpha$ and IL-12) was detected. T7 dose-dependently increased TNF- $\alpha$ and IL-12 from 5 to $40 \mu \mathrm{M}(5-10 \mu \mathrm{M} 4 \mathrm{~T} 7$ is equal to $20-40 \mu \mathrm{M} \mathrm{T} 7)$. Compared with T7 and 4T7, distinctly higher levels of cytokines were recognized in the T7 - ML and T7 - MB groups, i.e., the $\mathrm{T} 7$ and $\mathrm{MB}$ conjugation was much more potent than T7 or MB alone. Furthermore, the conjugated branched epitope had a stronger stimulating ability on BMDCs than the linear epitope, as the TNF- $\alpha$ and IL-12 levels were more efficiently enhanced by the T7 - MB group than by the T7 - ML group.

\section{Tumor inhibition and immunogenicity stimulation of the vaccines}

A tumor challenge model was established in vivo by the subcutaneous inoculation of EAC cells into BALB/c 
<smiles>COCCOc1nc(N)c2nc(O)n(Cc3ccc(CNC(=O)CCC(=O)O)cc3)c2n1</smiles>

\author{
KPHVHTKPHVHTKPHVHTKPHVHTK \\ $\langle\mathrm{ML}$ ।
}

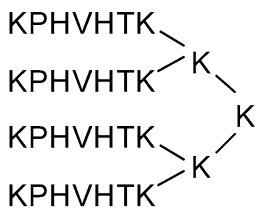

$\langle\mathrm{MB}$ ।
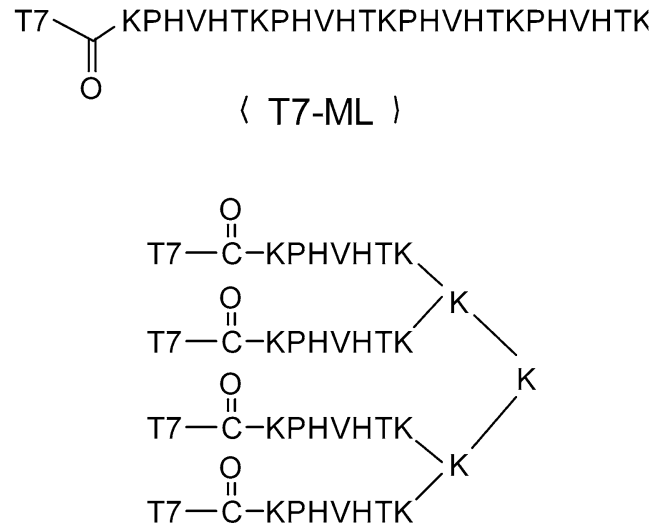

$\langle\mathrm{T} 7-\mathrm{MB}|$

Fig. 2 Chemical structures of the synthetic vaccines
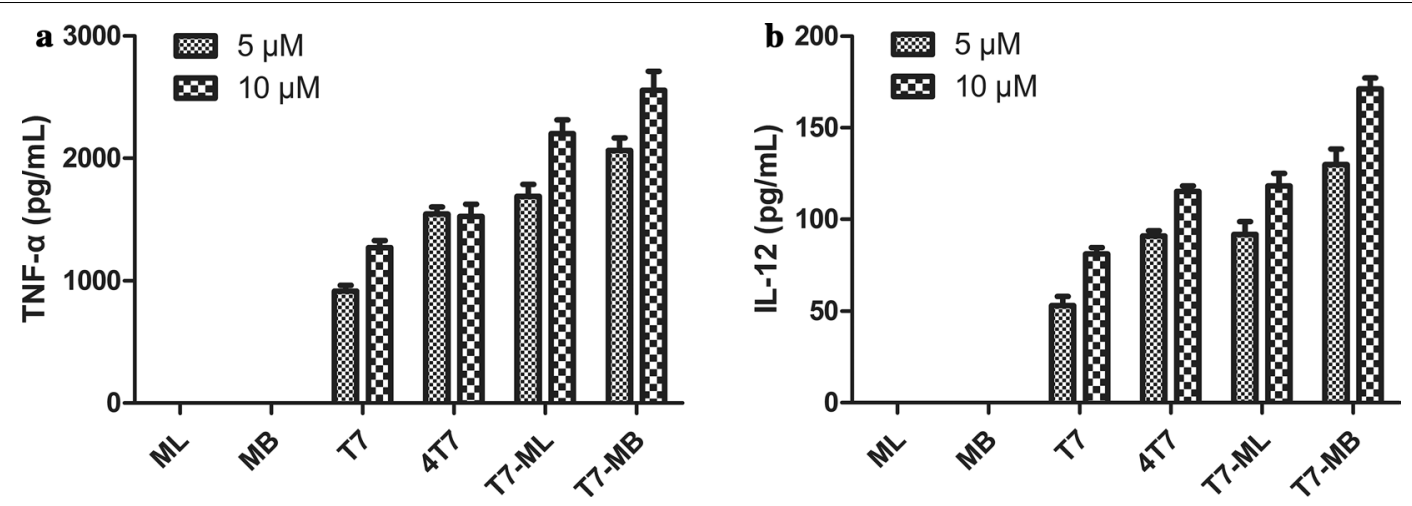

Fig. 3 Vaccines induced the cytokine release of mouse bone marrow dendritic cells (BMDCs) in vitro. BMDCs of BALB/c mice were incubated with the vaccines for $24 \mathrm{~h}$, and mouse TNF-a (a) and IL-12 (b) levels were quantified by ELISA. 4T7 represents the 4-fold concentration of T7, which was compared with T7 - MB since $4 \mathrm{~mol}$ of T7 were conjugated to 1 mol of MB in T7 - MB. The data represent the mean $\pm \operatorname{SE}(n=3)$

mice to explore the prophylactic abilities of the vaccines. Herein, EAC cells represented a type of mouse ascites carcinoma that expresses MG7-Ag at high levels, which was affirmed by western blot (Additional file 5). Four equal molar quantities of T7 (4T7) contrasted the branched epitope groups ( $77+\mathrm{MB}$ and $\mathrm{T} 7-\mathrm{MB})$. Compared with the PBS control, immunization with
T7, ML or MB alone every 2 weeks three times had no apparent effect on tumor development. Reductions in tumor weights were clearly observed when T7 was used in combination with the MG7-Ag tetra-epitope (ML or MB) (Fig. 4a). In addition, comparing four vaccines $(\mathrm{T} 7+\mathrm{ML}, \mathrm{T} 7-\mathrm{ML}, \mathrm{T} 7+\mathrm{MB}$ and $\mathrm{T} 7-\mathrm{MB})$ showed that the branched epitope better improved the 

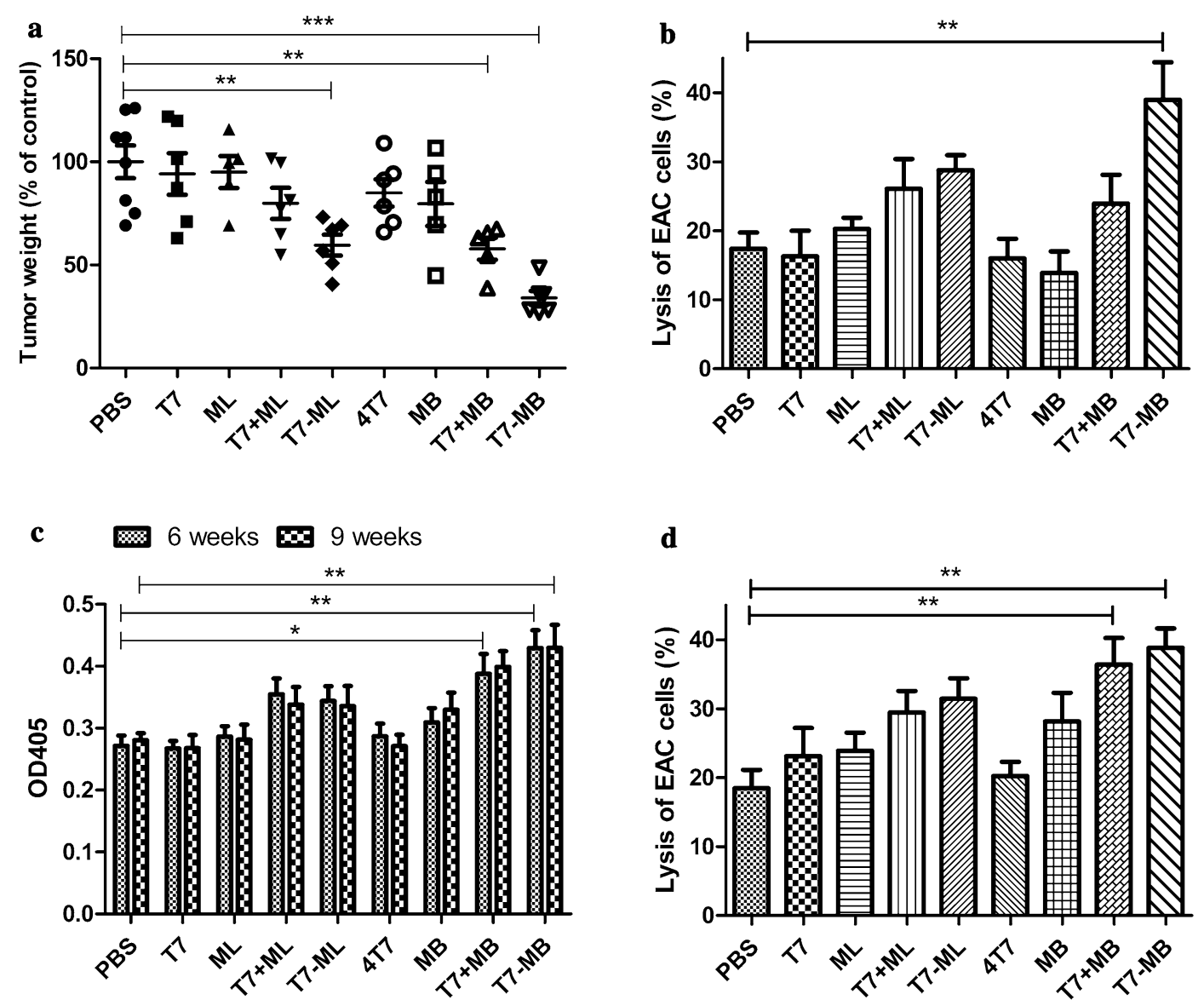

Fig. 4 Effects of the vaccines on tumor inhibition and immunogenicity stimulation in BALB/c mice ( $n \geq 5 /$ group). a EAC tumor burdens were reduced by the vaccines, where the PBS control (100\%) was $1.06 \pm 0.08 \mathrm{~g}$. b Cytotoxic T cell responses were induced by the vaccines, as indicated by the lysis of EAC cells using the LDH method. c Serum antibodies against MG7-Ag induced by the vaccines after immunization (6 weeks) and after sacrifice ( 9 weeks), as determined by ELISA. $\mathbf{d}$ Antibody-dependent cell-mediated cytotoxicity (ADCC) effects induced by the vaccines, as indicated by the lysis of EAC cells using the LDH method. The data represent the mean $\pm S E ;{ }^{*} P<0.05$, ${ }^{* *} P<0.01$ and ${ }^{* * *} P<0.001$ compared to the PBS control group

antitumor properties than the linear epitope, while T7 and the epitope in chemical conjugation was more efficient than the simple commixture. Next, CTL activity was measured to determine cellular immunity activations in vaccinated BALB/c mice. As shown in Fig. $4 \mathrm{~b}$, T7 and the MG7-Ag tetra-epitope in combination had a significantly higher lytic activity than the PBS control, whereas the lytic activities of $\mathrm{T} 7, \mathrm{ML}$ alone and $\mathrm{MB}$ alone did not differ from that of the control. Similar to the tumor inhibition results, T7 $-\mathrm{MB}$, constructed with the branched epitope and chemical conjugation, had the highest cytotoxicity among all the vaccines. For the impacts on humoral immunity, serum antibody titers of the vaccinations against MG7-Ag were first judged by the ELISA method. No distinct differences in antibodies were detected at 2 or 4 weeks after first immunization (data not shown).
Six and nine weeks later, the MG7-Ag antibodies displayed marked increases in the T7 + ML, T7 - ML, $\mathrm{T} 7+\mathrm{MB}$ and $\mathrm{T} 7-\mathrm{MB}$ groups, and the vaccines constructed with $\mathrm{MB}$ elicited more potent responses than those constructed with ML. However, the differences between 6 and 9 weeks and between simple commixture and chemical conjugation were negligible (Fig. 4c). ADCC activity was also assessed by adding NK cells and serum samples to tumor cells. Antibodies derived from $\mathrm{T} 7-\mathrm{MB}$ induced the most powerful cancer cell lysis, but the differences in ADCC activity between the simple commixture $(\mathrm{T} 7+\mathrm{MB})$ and chemical conjugation $(\mathrm{T} 7-\mathrm{MB})$ samples were not as significant as those between their CTL activities (Fig. 4d). No remarkable CTL or ADCC effects on the vaccines were found when mouse breast cancer 4T1 cells were used as target cells for the negative control (data not shown). 


\section{Synergistic effects of 5-FU and T7 - MB on tumor inhibition using the prophylactic schedule}

Since T7 - MB was the most effective vaccine in this study, the synergistic effects of T7 - MB and 5-FU (a typical chemotherapeutic agent) on tumor challenge were further examined in vivo. Substantially more potent inhibitory effects on tumor sizes were observed upon the combination treatment of 5-FU and T7 - MB administered on the prophylactic schedule compared with those observed with control or single treatments. As shown in Fig. 5a, T7 - MB inhibited tumor volumes more efficiently than 5-FU in EAC tumor-challenged mice, and further shrinkage was increasingly clear upon the simultaneous administration of 5-FU and T7 - MB from days 1 through 21. Regarding tumor weights, $25.82 \%$ of the combination treatment group was statistically significantly different from the control group (100.00\%), the 5-FU group (69.26\%) and the T7 - MB group (34.02\%) (Fig. 5b). Figure $5 \mathrm{c}$ shows that the first mouse death was reported in the control group on day 28. The last deaths in the control and 5-FU groups occurred on days 38 and 48 , respectively. Compared with the T7 - MB group (33.33\% mice surviving longer than 70 days), the combination treatment group $(50.00 \%)$ exhibited substantially increased long-term survival rates during a 70-day observation period.

The CTL activities of the BALB/c mice were first investigated to uncover the mechanisms exerted by the simultaneous application of 5-FU and T7 - MB administered on the prophylactic schedule, and the results are illustrated in Fig. 6a. Although 5-FU alone induced CTLs to a certain degree, the difference between 5-FU and the PBS control was not significant. As expected, CTLs activated by the combination treatment group had obviously higher cytotoxicity values (48.86\%) than those of CTLs activated by 5 -FU (21.37\%) and T7 - MB (38.99\%) alone.
Variances in the $\mathrm{T}$ cell subsets of mice splenic lymphocytes were then demonstrated by flow cytometry. As shown in Fig. $6 \mathrm{~b}, \mathrm{c}$, the percentage of $\mathrm{CD}^{+} / \mathrm{CD}^{+} \mathrm{T}$ cells in the T7 - MB group (15.25\%) was higher than those in the 5-FU (13.02\%) and PBS (10.18\%) groups. The CD8 ${ }^{+}$ $\mathrm{T}$ cell ratio increased significantly to $18.78 \%$ in the combination treatment group compared to that in the 5-FU and T7 - MB groups, which was consistent with the CTL results. $\mathrm{CD} 44^{+} \mathrm{T}$ cells had an outcome similar to that of $\mathrm{CD}^{+} \mathrm{T}$ cells, as $24.06 \%$ of the lymphocytes referred to $\mathrm{CD}^{+} / \mathrm{CD}^{+}{ }^{+} \mathrm{T}$ cells in the combination treatment group, which was much more potent than that in the 5-FU (16.15\%) and T7 - MB alone (18.59\%) groups (Fig. 6b, d). In addition, the ratios of $\mathrm{CD}^{+}$and $\mathrm{CD}^{+} \mathrm{T}$ cells in untreated naïve BALB/c mice were 14.87 and $19.01 \%$, respectively, which were approximately equal to those in the T7 - MB group (data not shown). We also examined the capacities of 5-FU and T7 - MB on the reductions of myeloid-derived suppressor cells (MDSCs). As displayed in Fig. 7, 5-FU alone had stronger inhibitory effects on MDSCs than T7 - MB alone, while the combination treatment further decreased the MDSCs ratio to $5.67 \%$. Untreated naïve BALB/c mice had merely 5.92\% MDSCs in their splenocytes (data not shown), which was similar to that in the combination treatment group.

\section{Synergistic effects of 5-FU and T7 - MB on tumor inhibition using the therapeutic schedule}

The therapeutic effects of the vaccines were assessed by subcutaneously challenging $\mathrm{BALB} / \mathrm{c}$ mice with tumor cells, followed by the drug administration of $\mathrm{T} 7-\mathrm{MB}$. Figure $8 \mathrm{a}$ shows that 5 -FU and T7 - MB administered on the therapeutic schedule exerted some inhibitory effects on tumor size and volume. The simultaneous administration of 5-FU and T7 - MB gradually induced significant tumor shrinkage from days 1 through day 21 compared
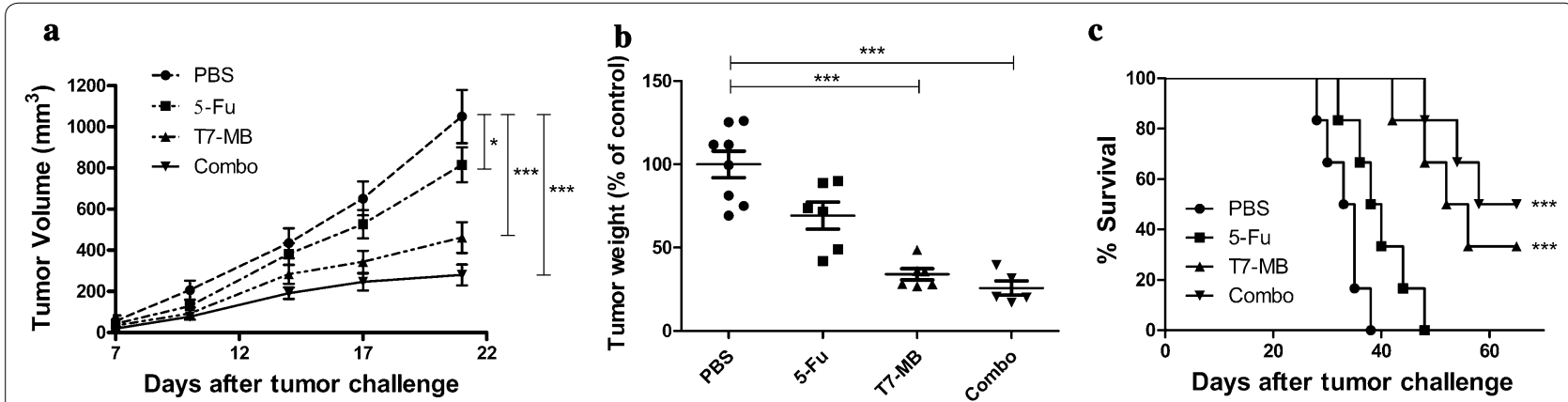

Fig. 5 Additive effects of 5-FU and T7 - MB on tumor inhibition using the prophylactic schedule ( $\mathrm{n} \geq 5$ mice/group). a Tumor growth curves displaying tumor volumes, where the dimensions were measured twice a week until day 21 (two-way ANOVA). b Tumor weights were determined at the time of sacrifice on day 21, where the PBS control (100\%) was $1.06 \pm 0.08 \mathrm{~g}$. c Survival curves indicating that post-treatment effects were exerted on tumor-bearing mice for more than 70 days (log-rank test). The data represent the mean $\pm S E ;{ }^{*} P<0.05$ and ${ }^{* * *} P<0.001$ compared to the PBS control group 

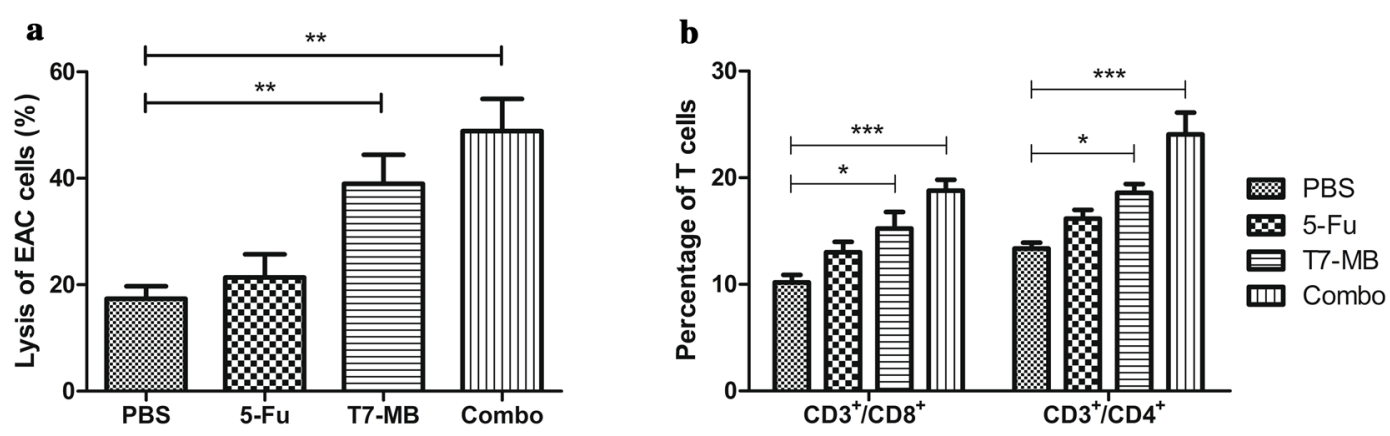

c
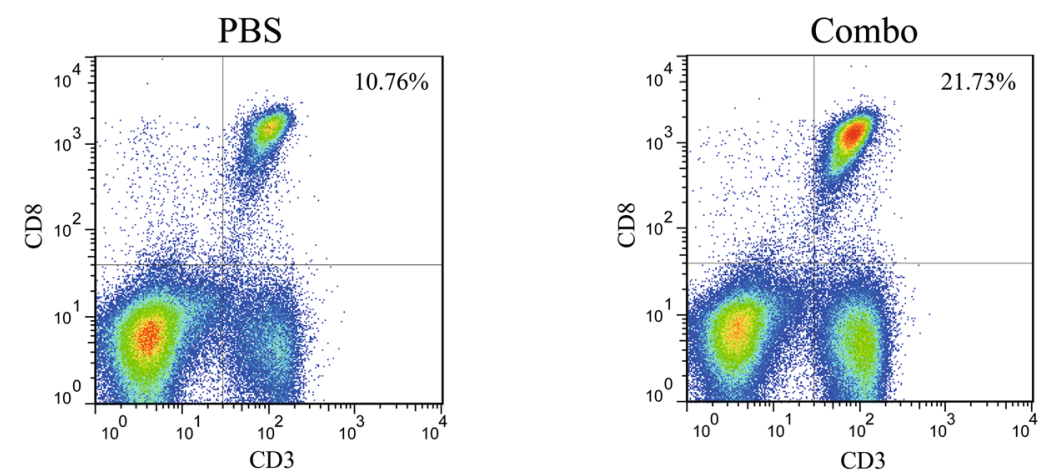

d

PBS
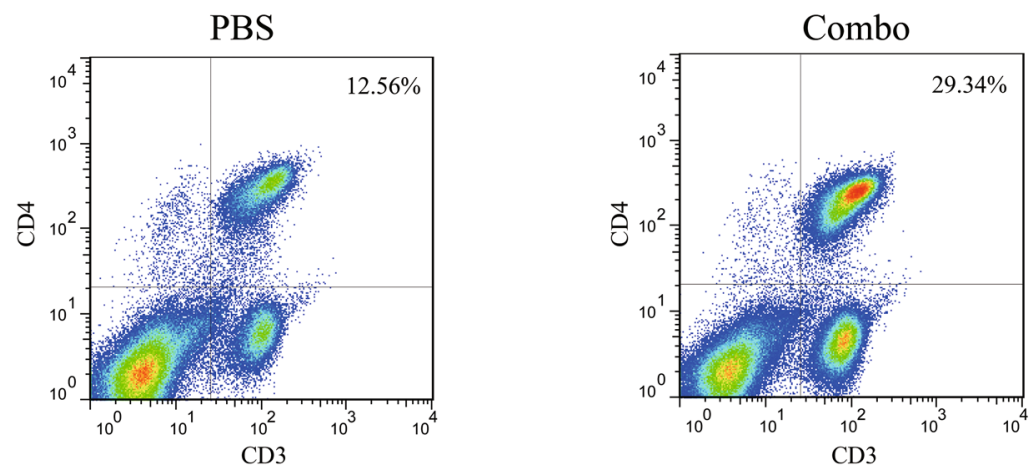

Fig. 6 Additive effects of 5-FU and T7 - MB on T cells using the prophylactic schedule ( $n \geq 5$ mice/group). a Cytotoxic T cell responses were induced by $5-\mathrm{FU}$ and T7 $-\mathrm{MB}$, as indicated by the lysis of EAC cells using the LDH method. $\mathbf{b}$ Increases in $\mathrm{CD} 8^{+}$and $\mathrm{CD} 4^{+} \mathrm{T}$ cells in splenic lymphocytes were induced by 5-FU and T7 - MB, as determined by flow cytometry. $\mathbf{c}$ Flow cytometry results of CD8 ${ }^{+} \mathrm{T}$ cells in splenic lymphocytes in the PBS control (left) and 5-FU and T7 - MB combination (right) groups. $\mathbf{d}$ Flow cytometry results of CD4 ${ }^{+} \mathrm{T}$ cells in splenic lymphocytes in the PBS control (left) and 5-FU and T7 - MB combination (right) groups. The data represent the mean $\pm \mathrm{SE} ;{ }^{*} P<0.05,{ }^{* *} P<0.01$ and ${ }^{* * *} P<0.001$ compared to the PBS control group

with that induced by 5 -FU or T7 - MB alone. In total, the tumor weights in the combination treatment group were $61.47 \%$ lower than those in the PBS control group, which was much lower than those in the 5-FU (72.45\%) and $\mathrm{T} 7-\mathrm{MB}(80.72 \%)$ groups (Fig. $8 \mathrm{~b})$. For the longterm survival rates, the final deaths of mice in the control, 5-FU and T7 - MB groups occurred on days 39, 47 and 50, respectively. Meanwhile, $16.67 \%$ of mice in the combination treatment group survived longer than 70 days (Fig. 8c). As shown in Fig. 9a, CTLs activated by the combination treatment displayed remarkably higher cytotoxicity (31.15\%) than those in the PBS control group (20.38\%), while the CTLs of the 5-FU and T7 - MB alone groups were not significantly different from those of the PBS control group. Figure $9 \mathrm{~b}-\mathrm{d}$ shows $\mathrm{T}$ cell subsets in mouse splenic lymphocytes after drug administration, where the percentages of $\mathrm{CD}^{+} / \mathrm{CD}^{+}$and $\mathrm{CD} 3^{+} / \mathrm{CD} 4^{+}$ $\mathrm{T}$ cells in the combination treatment group were obviously higher than those in the 5-FU and T7 - MB alone groups. However, T7 - MB had little impact on MDSCs, 

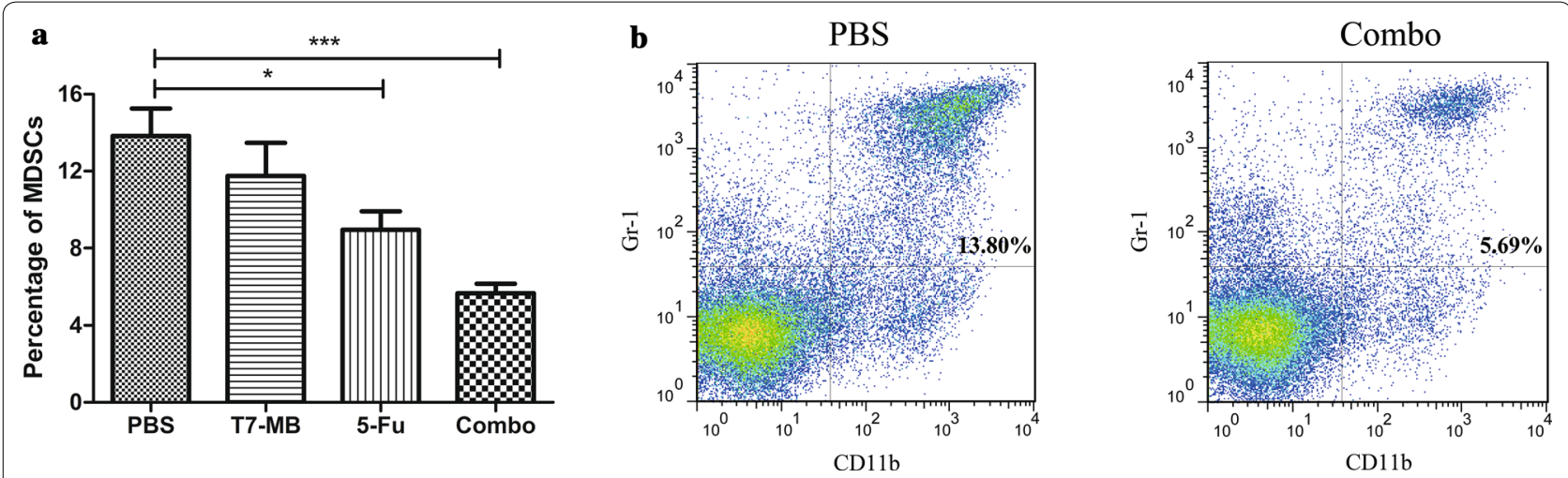

Fig. 7 Additive effects of 5-FU and T7 - MB on MDSCs using the prophylactic schedule ( $n \geq 5$ mice/group). a Decreases in MDSCs in splenic lymphocytes were induced by 5-FU and T7 - MB, as determined by flow cytometry. b Flow cytometry results of MDSCs in splenic lymphocytes in the PBS control (left) and 5-FU and T7 - MB combination (right) groups. The data represent the mean \pm SE; ${ }^{*} P<0.05$ and ${ }^{* *} P<0.001$ compared to the PBS control group

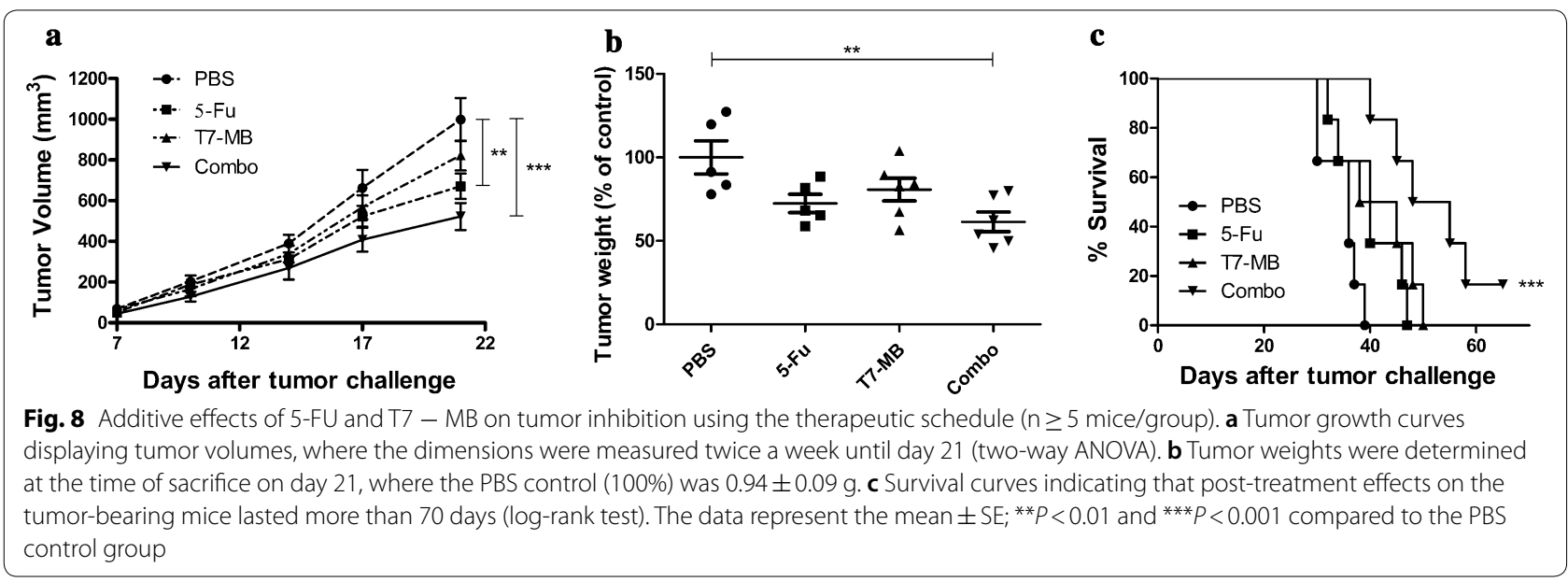

and no significant difference in MDSCs was detected between the combination treatment group and the 5-FU alone group (data not shown).

\section{Discussion}

Gastric cancer is the fifth leading cause of cancer and the third leading cause of death from cancer, comprising $7 \%$ of cases and $9 \%$ of deaths [14]. Traditional treatment for gastric cancer may include surgery, chemotherapy and radiation therapy. Currently, new approaches, especially immunotherapy, are being intensively investigated due to their advantages of effective targeting and few side effects [15]. In particular, trastuzumab represents the first target molecule that improves overall survival in human epithelial growth factor receptor-2 (HER2)-positive gastric cancer patients $[16,17]$. A range of tyrosine-kinase inhibitors (sunitinib, apatinib, lapatinib, etc.) and monoclonal antibodies (bevacizumab, pertuzumab, etc.), aimed at vascular epithelial growth factor receptor (VEGFR), epithelial growth factor receptor (EGFR), the PI3K-AKT-mTOR pathway and the HGF-c-Met pathway, are also under investigation with promising results [18-20]. Immune checkpoint inhibitors, which represent a landmark innovation in malignant melanoma and non-small cell lung cancer therapies, are another measure to effectively treat gastric cancer [21]. A phase I clinical trial has been completed on a population of patients with PD-L1-positive gastric cancer, and pembrolizumab (a PD-1 antibody) has antitumor activity and manageable toxicity, warranting further phase II and III trials [22].

Tumor vaccines also play an important role in cancer therapy by stimulating the immune system to find and kill tumor cells. Sipuleucel-T, the first cell-based immunotherapeutic vaccine approved by the FDA, has been shown to improve the survival of patients with asymptomatic or minimally symptomatic metastatic castration-resistant prostate cancer (mCRPC) via initiating immune responses to prostatic acid phosphate (PAP) 

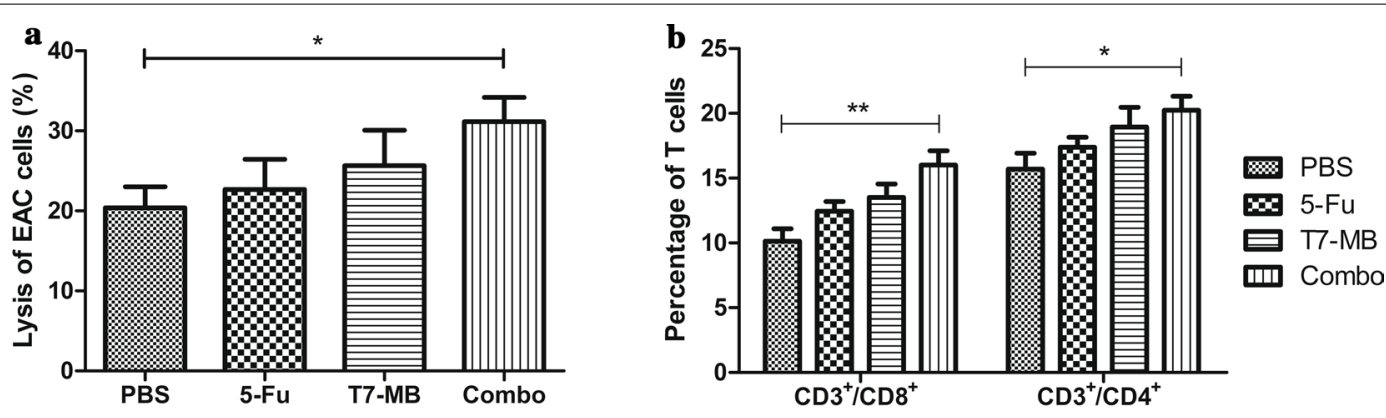

c
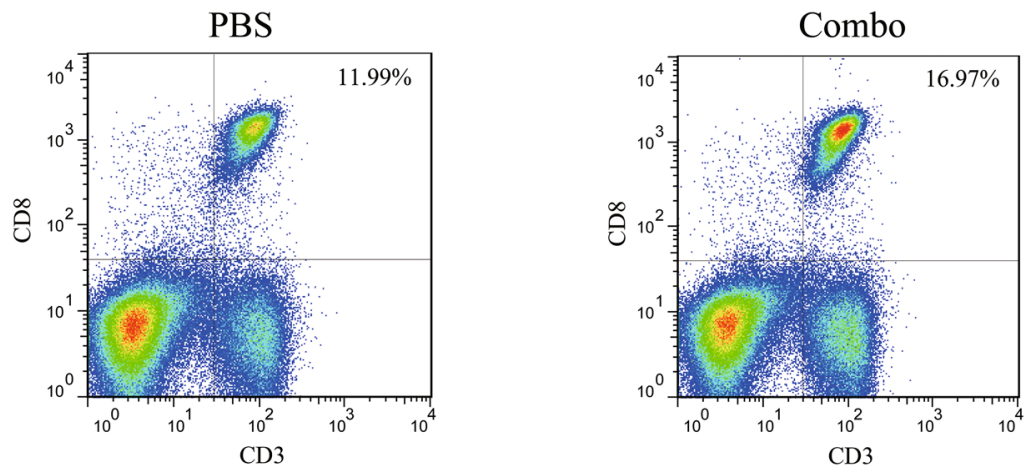

d
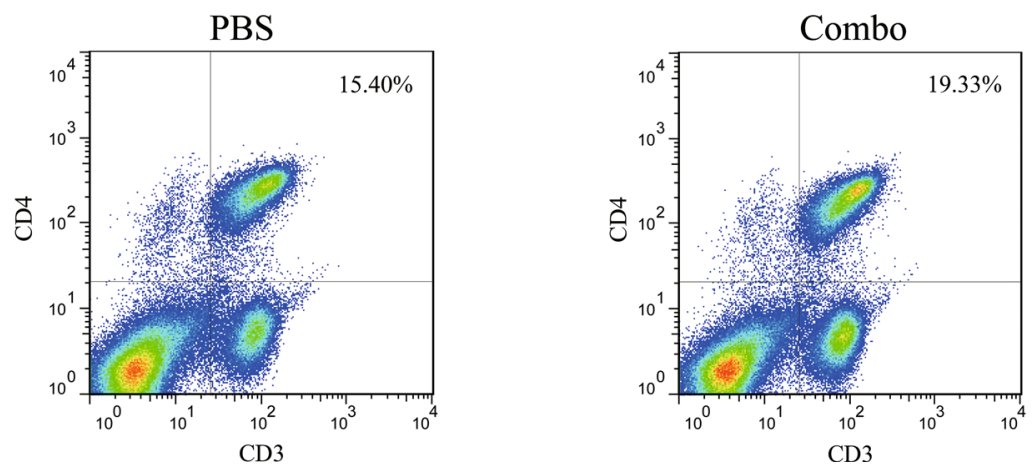

Fig. 9 Additive effects of 5-FU and T7 - MB on T cells using the therapeutic schedule ( $n \geq 5$ mice/group). a Cytotoxic T cell responses were induced by $5-\mathrm{FU}$ and $\mathrm{T7}-\mathrm{MB}$, as indicated by the lysis of EAC cells using the LDH method. $\mathbf{b}$ Increases in CD8 ${ }^{+}$and $C D 4^{+} \mathrm{T}$ cells in splenic lymphocytes were induced by $5-\mathrm{FU}$ and $\mathrm{T} 7-\mathrm{MB}$, as determined by flow cytometry. $\mathbf{c}$ Flow cytometry results of $\mathrm{CD} 8^{+} \mathrm{T}$ cells in splenic lymphocytes in the PBS control (left) and 5-FU and T7 - MB combination (right) groups. $\mathbf{d}$ Flow cytometry results of CD4 ${ }^{+} \mathrm{T}$ cells in splenic lymphocytes in the PBS control (left) and 5-FU and T7 - MB combination (right) groups. The data represent the mean $\pm \mathrm{SE} ;{ }^{*} P<0.05$ and ${ }^{*} P<0.01$ compared to the PBS control group

[23]. Regarding gastric cancer, vaccines against Helicobacter pylori and VEGFR demonstrate favorable effects as both single immunotherapy agents and in combination with other chemotherapeutic agents [24, 25]. However, the development of gastric cancer vaccines is still preliminary because of the difficulties in identifying TAAs and adjuvants.

Our group has a strong background in researching tumor vaccines with applications of TLR7 agonists. We have demonstrated that conjugation of T7 and the OCT4 (octamer-binding transcription factor 4) protein was effective and safe in preventing tumor growth in xenografted mice [26]. We have also constructed gastric cancer vaccines with T7 and the MG7-Ag tri-epitope, displaying some effects on generating CTLs and ADCCmediating antibodies recognizing MG7-Ag [8]. Herein, to improve the efficiency of our vaccines, we developed novel gastric cancer vaccines utilizing MAPs of the MG7-Ag epitope (with either a linear or branched architecture). Branched MAPs aimed at enhancing immune responses against tumor cells, including MAPs based on CTL epitopes of human telomerase reverse transcriptase 
(hTERT), are clearly observable [27]. In vitro, our smallmolecule compound $\mathrm{T} 7$ improved innate immunity in BMDCs in a concentration-dependent manner by inducing the inflammatory mediators TNF- $\alpha$ and IL- 12 . The combination of ML or MB with T7 yielded much more potent effects, although neither ML nor MB alone impacted cytokine secretion to any notable extent. Moreover, the branched architecture of the MG7-Ag epitope and its chemical conjugation to T7 (T7 - MB) had the most notable BMDC stimulatory activity (Fig. 3). Cytokines can further activate the expression of costimulatory molecules to assist interactions between antigenpresenting cells (APCs) and T and B cells [28]. Thus, we further investigated the impacts of our vaccines on adaptive immunity in vivo, assessing CTLs, antibodies, etc. Figure $4 \mathrm{~b}-\mathrm{d}$ suggests that $\mathrm{T} 7 \mathrm{-MB}$ elicited remarkable $\mathrm{T}$ lymphocyte cytotoxicity and IgG antibodies to specifically lyse EAC cancer cells. Indeed, T7 - MB was the most effective agent at reducing the tumor burden in vivo (Fig. 4a), which was also consistent with the in vitro results. We have reported the importance of covalently attaching the TLR7 agonist and the MG7-Ag epitope to designing gastric cancer vaccines [8]. Here, we proved that the branched MAP structure could further elevate the efficacies of tumor inhibition and immune stimulation, leading to a brand-new vaccine, T7 - MB.

Recently, immunochemotherapy, achieved by combining a chemotherapeutic agent with an immune-modulating agent, has become an appealing approach to cancer therapy [29]. Heterologous strategies, i.e., combination of remedies that activate immunity via different mechanisms, are distinctly preferred over homologous strategies because they not only require decreased drug dosages and reduce side effects but they also reduce chemo- and immunoresistance incidence rates [30]. For example, Iinuma et al. conducted a phase I clinical study on esophageal cancer patients, certifying the safe and satisfactory long-term therapeutic outcomes of peptide vaccination plus chemoradiation [31]. Although chemotherapies are commonly considered to act via cytotoxic pathways, accumulating evidence proves that immune responses can also be elicited by chemotherapeutic agents, contributing to the final antitumor effects [32, 33]. 5-Fluorouracil (5-FU), a clinically well-established medication, is administered either systemically for the treatment of colorectal, stomach and breast cancers or topically for skin cancer treatment. 5-FU is also reported to potently and selectively kill tumor-associated MDSCs and improve $\mathrm{T}$ cell-dependent responses in vivo [34]. MDSCs promote tumor growth by favoring tumor cell survival and creating an immunosuppressive microenvironment, which may severely destroy the efficacy of vaccines. We hypothesized that the inhibition of MDSCs by
5-FU was beneficial to the immunostimulatory properties generated by our vaccines. Therefore, we performed further research on the synergistic usage of our vaccine (T7 - MB) with 5-FU, attempting to fully understand their antitumor effects and mechanisms.

5-FU treatment (every 3 days after tumor implantation) demonstrated cytotoxicity by decreasing tumor sizes and weights and increasing survival time, although the effects were still weaker than those of $\mathrm{T} 7 \mathrm{-MB}$ vaccination. Substantially more significant results were observed when 5-FU and T7 - MB were applied in combination (Fig. 5). Furthermore, the CTL activity of the combination group was clearly higher than that in both the 5 -FU and T7 - MB groups (Fig. 6a). However, no differences were observed between the groups with and without 5-FU in the determination of MG7-Ag antibody titers and ADCC activity (data not shown), indicating that 5 -FU improved the $\mathrm{T}$ cell responses induced by $\mathrm{T} 7-\mathrm{MB}$ rather than improving $\mathrm{B}$ cell responses. The $\mathrm{CD} 8^{+}$and $\mathrm{CD}^{+}$subsets are the two main $\mathrm{T}$ cells populations and play critical roles in host defenses against cancer. Upon stimulation, naïve $\mathrm{CD}^{+} \mathrm{T}$ cells can differentiate into memory and effector $\mathrm{CD} 8^{+} \mathrm{T}$ cells, while naïve $\mathrm{CD} 4^{+} \mathrm{T}$ cells can differentiate into $\mathrm{T}$ helper (Th) type $1, \mathrm{Th} 2$ and Th17 cells [35]. As displayed in Fig. 6b-d, compared to the PBS control, T7 - MB vaccination markedly augmented the proportions of both $\mathrm{CD}^{+} / \mathrm{CD}^{+}$and $\mathrm{CD}^{+} /$ $\mathrm{CD}^{+} \mathrm{T}$ cells in splenocytes, which were further elevated by the combinational usage of 5-FU despite the limited function of 5-FU alone. Regarding MDSCs, 5-FU

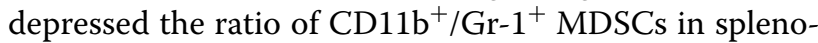
cytes treated with $\mathrm{T} 7-\mathrm{MB}$ (Fig. 7), which contributed to the synergistic antitumor potency. In addition to the prophylactic benefits, therapeutic tumor vaccines are also prospective. For example, GTL001 induced strong antigen-specific $\mathrm{T}$ cell responses and tumor eradications in a curative strategy when adjuvanted with a TLR7 agonist [36]. Similarly, we detected the therapeutic consequences of our vaccine, T7 - MB, as well as those of 5-FU. Even though T7 - MB and 5-FU alone did not sufficiently impact tumor repression, tumors in the combination group were significantly different from those in the PBS control group (Fig. 8). The CTL activity and percentages of $\mathrm{CD}^{+} / \mathrm{CD}^{+}$and $\mathrm{CD}^{+} / \mathrm{CD}^{+}{ }^{+} \mathrm{T}$ cells were also ameliorated when mice were treated with $\mathrm{T} 7-\mathrm{MB}$ and 5-FU together (Fig. 9).

\section{Conclusions}

In conclusion, we certified the application of TLR7 agonists and the MAP structure in the design of gastric cancer vaccines, with $\mathrm{T} 7-\mathrm{MB}$ providing benefits to tumor-bearing mice via CTLs and ADCC-mediating antibodies recognizing MG7-Ag. In addition, the synergistic 
antitumor functions of $\mathrm{T} 7-\mathrm{MB}$ and 5-FU were carefully examined, revealing that the prophylactic schedule was much more efficacious than the therapeutic schedule, and $\mathrm{T}$ cell responses played more important roles than $\mathrm{B}$ cell responses. MDSCs down-regulated by 5 -FU were also important for promoting the effects of $\mathrm{T} 7-\mathrm{MB}$. Although the specific dosage regimen of T7 - MB could be further optimized to maximize antitumor outcomes, we herein demonstrated the potentials of the construction and immunochemotherapy of our novel vaccine in cancer treatment schemes.

\section{Additional files}

Additional file 1. TIF High performance liquid chromatography (a) and mass spectrometry (b) of $\mathrm{ML}$.

Additional file 2. TIF High performance liquid chromatography (a) and mass spectrometry (b) of T7 - ML.

Additional file 3. TIF High performance liquid chromatography (a) and mass spectrometry (b) of $\mathrm{MB}$.

Additional file 4. TIF High performance liquid chromatography (a) and mass spectrometry (b) of T7 - MB.

Additional file 5. TIF The presence of MG7-Ag in EAC cells confirmed by western blot. 4T1 mouse breast cancer cell line was used as a negative control.

\section{Abbreviations}

TLR: Toll-like receptor; MDSC: Myeloid-derived suppressor cell; MG7-Ag: Monoclonal gastric cancer 7 antigen; 5-FU: 5-Fluorouracil; CTL: Cytotoxic T lymphocyte; ADCC: Antibody-dependent cell-mediated cytotoxicity; LDH: Lactate dehydrogenase; BMDC: Bone marrow dendritic cell; EAC: Ehrlich ascites carcinoma; TAA: Tumor-associated antigen; MAP: Multiple antigen peptide.

\section{Authors' contributions}

GJ and XW designed the research. XW, YL, YD, NG, YW and JZ performed the research. XW, HZ and ZW analyzed the data. XW wrote the manuscript. All authors read and approved the final manuscript.

\section{Author details}

1 School of Pharmaceutical Sciences, Shenzhen University Health Science Center, Shenzhen 518060, Guangdong, China. ${ }^{2}$ Cancer Research Center, Shenzhen University Health Science Center, Shenzhen 518060, Guangdong, China. ${ }^{3}$ The 3rd Affiliated Hospital of Shenzhen University, Shenzhen 518001, Guangdong, China. ${ }^{4}$ Department of Biology and School of Medicine, Southern University of Science and Technology, Shenzhen 518055, Guangdong, China.

\section{Acknowledgements}

Not applicable.

\section{Competing interests}

The authors declare that they have no competing interests.

\section{Availability of data and material}

The datasets used and/or analysed during the current study are available from the corresponding author on reasonable request.

\section{Consent for publication}

Not applicable.

\section{Ethics approval and consent to participate}

The animal protocols were approved by the Laboratory Animal Ethics Committee of Shenzhen University.

\section{Funding}

This work was supported by the National Natural Science Foundation of China (Grant No. 81202396).

\section{Publisher's Note}

Springer Nature remains neutral with regard to jurisdictional claims in published maps and institutional affiliations.

Received: 17 March 2018 Accepted: 30 April 2018

Published online: 08 May 2018

References

1. Vacchelli E, Eggermont A, Sautes-Fridman C, Galon J, Zitvogel L, Kroemer G, Galluzzi L. Trial Watch: Toll-like receptor agonists for cancer therapy. Oncoimmunology. 2013;2:e25238.

2. Vacchelli E, Galluzzi L, Eggermont A, Fridman WH, Galon J, SautesFridman C, Tartour E, Zitvogel L, Kroemer G. Trial watch: FDA-approved Toll-like receptor agonists for cancer therapy. Oncoimmunology. 2012;1:894-907.

3. Papadavid E, Stratigos AJ, Falagas ME. Imiquimod: an immune response modifier in the treatment of precancerous skin lesions and skin cancer. Expert Opin Pharmacother. 2007:8:1743-55.

4. Hibbitts S. TA-CIN, a vaccine incorporating a recombinant HPV fusion protein (HPV16 L2E6E7) for the potential treatment of HPV16-associated genital diseases. Curr Opin Mol Ther. 2010;12:598-606.

5. Smith BD, Kasamon YL, Kowalski J, Gocke C, Murphy K, Miller CB, GarrettMayer E, Tsai HL, Qin L, Chia C, Biedrzycki B, Harding TC, Tu GH, Jones R, Hege K, Levitsky HI. K562/GM-CSF immunotherapy reduces tumor burden in chronic myeloid leukemia patients with residual disease on imatinib mesylate. Clin Cancer Res. 2010;16:338-47.

6. O'Neill LA, Bowie AG. The family of five: TIR-domain-containing adaptors in Toll-like receptor signalling. Nat Rev Immunol. 2007;7:353-64.

7. Wu CC, Hayashi T, Takabayashi K, Sabet M, Smee DF, Guiney DD, Cottam HB, Carson DA. Immunotherapeutic activity of a conjugate of a Toll-like receptor 7 ligand. Proc Natl Acad Sci USA. 2007;104:3990-5.

8. Wang XD, Gao NN, Diao YW, Liu Y, Gao D, Li W, Wan YY, Zhong JJ, Jin GY. Conjugation of Toll-like receptor-7 agonist to gastric cancer antigen MG7Ag exerts antitumor effects. World J Gastroenterol. 2015;21:8052-60.

9. Zhu J, He S, Du J, Wang Z, Li W, Chen X, Jiang W, Zheng D, Jin G. Local administration of a novel Toll-like receptor 7 agonist in combination with doxorubicin induces durable tumouricidal effects in a murine model of T cell lymphoma. J Hematol Oncol. 2015;8:21.

10. Zhang D, Chen Y, Fan D. MG7 mimotope-based DNA vaccination for gastric cancer. Expert Rev Vaccines. 2006:5:223-31.

11. Fan D, Zhang X, Chen X, Mou Z, Hu J, Zhou S, Ding J, Wu K. Bird's-eye view on gastric cancer research of the past 25 years. J Gastroenterol Hepatol. 2005;20:360-5

12. Guo DL, Dong M, Wang L, Sun LP, Yuan Y. Expression of gastric cancerassociated MG7 antigen in gastric cancer, precancerous lesions and $\mathrm{H}$. pylori -associated gastric diseases. World J Gastroenterol. 2002;8:1009-13.

13. Liu J, Hu JL, Zhang XY, Qiao TD, Chen XT, Wu KC, Ding J, Fan DM. The value of MG7 antigen in predicting cancerous change in dysplastic gastric mucosa. Int J Clin Pract. 2002:56:169-72.

14. Sun W, Yan L. Gastric cancer: current and evolving treatment landscape. Chin J Cancer. 2016:35:83.

15. De Vita F, Di Martino N, Fabozzi A, Laterza MM, Ventriglia J, Savastano B, Petrillo A, Gambardella V, Sforza V, Marano L, Auricchio A, Galizia G, Ciardiello F, Orditura M. Clinical management of advanced gastric cancer: the role of new molecular drugs. World J Gastroenterol. 2014;20:14537-58.

16. Bang YJ, Van Cutsem E, Feyereislova A, Chung HC, Shen L, Sawaki A, Lordick F, Ohtsu A, Omuro Y, Satoh T, Aprile G, Kulikov E, Hill J, Lehle M, Ruschoff J, Kang YK. ToGA Trial Investigators. Trastuzumab in combination with chemotherapy versus chemotherapy alone for treatment of HER2-positive advanced gastric or gastro-oesophageal junction cancer (ToGA): a phase 3, open-label, randomised controlled trial. Lancet. 2010:376:687-97. 
17. Sliwkowski MX, Lofgren JA, Lewis GD, Hotaling TE, Fendly BM, Fox JA. Nonclinical studies addressing the mechanism of action of trastuzumab (Herceptin). Semin Oncol. 1999;26:60-70.

18. Chen LT, Oh DY, Ryu MH, Yeh KH, Yeo W, Carlesi R, Cheng R, Kim J, Orlando $M$, Kang YK. Anti-angiogenic therapy in patients with advanced gastric and gastroesophageal junction cancer: a systematic review. Cancer Res Treat. 2017;49:851-68.

19. Kawakami H, Okamoto I. MET-targeted therapy for gastric cancer: the importance of a biomarker-based strategy. Gastric Cancer. 2016;19:687-95

20. Oh DY, Bang YJ. Pertuzumab in gastrointestinal cancer. Expert Opin Biol Ther. 2016;16:243-53.

21. Moehler M, Delic M, Goepfert K, Aust D, Grabsch HI, Halama N, Heinrich B, Julie C, Lordick F, Lutz MP, Mauer M, Alsina Maqueda M, Schild H, Schimanski CC, Wagner AD, Roth A, Ducreux M. Immunotherapy in gastrointestinal cancer: recent results, current studies and future perspectives. Eur J Cancer. 2016;59:160-70.

22. Muro K, Chung HC, Shankaran V, Geva R, Catenacci D, Gupta S, Eder JP, Golan T, Le DT, Burtness B, McRee AJ, Lin CC, Pathiraja K, Lunceford J, Emancipator K, Juco J, Koshiji M, Bang YJ. Pembrolizumab for patients with PD-L1-positive advanced gastric cancer (KEYNOTE-012): a multicentre, open-label, phase 1b trial. Lancet Oncol. 2016;17:717-26.

23. Hu R, George DJ, Zhang T. What is the role of sipuleucel-T in the treatment of patients with advanced prostate cancer? An update on the evidence. Ther Adv Urol. 2016;8:272-8.

24. Masuzawa T, Fujiwara Y, Okada K, Nakamura A, Takiguchi S, Nakajima K, Miyata H, Yamasaki M, Kurokawa Y, Osawa R, Takeda K, Yoshida K, Tsunoda T, Nakamura Y, Mori M, Doki Y. Phase I/II study of S-1 plus cisplatin combined with peptide vaccines for human vascular endothelial growth factor receptor 1 and 2 in patients with advanced gastric cancer. Int J Oncol. 2012:41:1297-304

25. Abadi ATB. Vaccine against Helicobacter pylori: inevitable approach. World J Gastroenterol. 2016:22:3150-7.

26. Lin G, Wang X, Yi W, Zhang C, Xu G, Zhu X, Cai Z, Liu Y, Diao Y, Lin MC, Jin $G$. A conjugate of octamer-binding transcription factor 4 and Toll-like receptor 7 agonist prevents the growth and metastasis of testis embryonic carcinoma. J Transl Med. 2015;13:166.
27. Liao ZL, Tang XD, Lu MH, Wu YY, Cao YL, Fang DC, Yang SM, Guo H. Antitumor effect of new multiple antigen peptide based on HLA-A0201-restricted CTL epitopes of human telomerase reverse transcriptase (hTERT). Cancer Sci. 2012;103:1920-8.

28. Lakshminarayanan $\mathrm{V}$, Thompson P, Wolfert MA, Buskas T, Bradley JM, Pathangey LB, Madsen CS, Cohen PA, Gendler SJ, Boons GJ. Immune recognition of tumor-associated mucin $\mathrm{MUC} 1$ is achieved by a fully synthetic aberrantly glycosylated MUC1 tripartite vaccine. Proc Natl Acad Sci USA. 2012;109:261-6.

29. Chen Y, Xia R, Huang Y, Zhao W, Li J, Zhang X, Wang P, Venkataramanan R, Fan J, Xie W, Ma X, Lu B, Li S. An immunostimulatory dual-functional nanocarrier that improves cancer immunochemotherapy. Nat Commun. 2016:7:13443.

30. Vacchelli E, Prada N, Kepp O, Galluzzi L. Current trends of anticancer immunochemotherapy. Oncoimmunology. 2013;2:e25396.

31. Inuma H, Fukushima R, Inaba T, Tamura J, Inoue T, Ogawa E, Horikawa M, Ikeda Y, Matsutani N, Takeda K, Yoshida K, Tsunoda T, Ikeda T, Nakamura Y, Okinaga K. Phase I clinical study of multiple epitope peptide vaccine combined with chemoradiation therapy in esophageal cancer patients. J Transl Med. 2014;12:84

32. Zitvogel L, Apetoh L, Ghiringhelli F, Andre F, Tesniere A, Kroemer G. The anticancer immune response: indispensable for therapeutic success? J Clin Investig. 2008;118:1991-2001.

33. John J, Ismail M, Riley C, Askham J, Morgan R, Melcher A, Pandha H. Differential effects of Paclitaxel on dendritic cell function. BMC Immunol. 2010;11:14

34. Vincent J, Mignot G, Chalmin F, Ladoire S, Bruchard M, Chevriaux A, Martin F, Apetoh L, Rebe C, Ghiringhelli F. 5-Fluorouracil selectively kills tumor-associated myeloid-derived suppressor cells resulting in enhanced T cell-dependent antitumor immunity. Cancer Res. 2010;70:3052-61.

35. Jiang $S$, Yan W. T-cell immunometabolism against cancer. Cancer Lett. 2016;382:255-8.

36. Esquerre M, Momot M, Goubier A, Gonindard C, Leung-Theung-Long S, Misseri Y, Bissery MC. GTL001 and bivalent CyaA-based therapeutic vaccine strategies against human papillomavirus and other tumor-associated antigens induce effector and memory T-cell responses that inhibit tumor growth. Vaccine. 2017;35:1509-16.
Ready to submit your research? Choose BMC and benefit from:

- fast, convenient online submission

- thorough peer review by experienced researchers in your field

- rapid publication on acceptance

- support for research data, including large and complex data types

- gold Open Access which fosters wider collaboration and increased citations

- maximum visibility for your research: over $100 \mathrm{M}$ website views per year

At $\mathrm{BMC}$, research is always in progress.

Learn more biomedcentral.com/submissions 